- Personal care and support

- Night care

Although the elements of service are provided by different providers, they work together to ensure care is seamless 24/7.

Outcomes The GCP was commissioned as a "test and learn project"; now in it's $3^{\text {rd }}$ year, the service has developed in response to local need and resources have been flexibly allocated to provide responsive, high quality care.

Each provider has signed up to the success of the project and each has an equal stake in ensuring that the service meets its key performance indicators.

The project has succeeded in supporting an increase in home and hospice deaths and a reduction in hospital admissions, length of stay and deaths.

Application to hospice practice The model and contracting arrangements have attracted National interest amongst Hospices and commissioners, and has been cited as a model of good practice for others to build on.

Thinking strategically about the role of hospices

The GCP model is a natural extension of the Hospice service, producing efficiencies and quality improvements. With the current proposed model for palliative care funding, Hospices will need to take on the role as prime contractors in order to survive.

\section{P91 PARTNERSHIPS: A PUBLIC HEALTH INTERPRETATION OF LIVING WELL AND DYING WELL}

${ }^{1}$ Rachel Zammit, 'Siobhan Horton, ${ }^{2}$ Julie Atkin-Ward. 'St Luke's Cheshire Hospice, Winsford, UK, ${ }^{2}$ Macmillan Cancer Support, UK

\subsection{6/bmjspcare-2013-000591.113}

Aim The overarching aims of the Cheshire Living Well, Dying Well Programme are to improve health and well-being by supporting a change in public knowledge, attitude and behaviour towards death, dying and loss and therefore make living well and dying well the norm.

Background St. Luke's Cheshire Hospice engaged in a community consultation process which highlighted that local partner organisations supported a co-ordinated public health approach to raise awareness and change behaviours in relation to death and loss. St. Luke's secured funding and a commitment of engagement from Macmillan Cancer Support, which included establishing a dedicated role to centrally lead and drive forward the agenda in Cheshire.

Methodology As death, dying and loss is a cross-cutting issue, it is important that a multi-faceted approach is developed and delivered in partnership. It is also important that the work is championed and embedded at strategic, operational and community level. The programme of work provides structure and support to enable partners to work together towards achieving the shared aim.

Findings and Recommendations Following consultation, six strategic areas have been identified; Partnership and Strategy Development, Financial Housekeeping and Future Planning, Resource Development, Public Education, Compassionate Communities and Healthy Workplace.

The work is also being championed at Health and Well-being Board Level.

Highlights include:

The formal launch and implementation of Cheshire Living Well, Dying Well Partnership
Identification of Cheshire Living Well, Dying Well Champions

Development and implementation of a range of resources (including support and training sessions for the public, staff and volunteers)

Development and implementation of Compassionate Community Volunteer Models

Presentation of the Programme at a local, regional, national and international level

Conclusion Improving the well-being of communities by normalising death and loss is a multi-agency issue and not singularly confined to those in the health arena.

This innovative approach identifies and enables partnership activity and the collation of evidence to progress further, with a view to mainstreaming the work.

\section{P92 ISABEL HOSPICE BENEFITS ADVISOR PARTNERSHIP}

Lesley Ford, Helen Dodd. Isabel Hospice, Welwyn Garden City, UK

\subsection{6/bmispcare-2013-000591.114}

Isabel Benefits Advisor and East Herts Citizens Advice Service Partnership and supported by the Big Lottery Fund.

The partnership between the Isabel Hospice and East Herts Citizens Advice Service (EHCAS) was formed in 2010 to enhance the services for patients assessed as requiring support for financial, legal matters, employment, utilities, debt, housing, immigration and nationality, taxation and discrimination as well as relationship advice to ensure that the most up to date information is made available.

Evidence has shown that people living with life limiting illness such as cancer do not receive benefits and other forms of support for which they are eligible. The complexities of the welfare system can seem overwhelming at a time when they are struggling to come to terms with their situation. Isabel Hospice is the service provider for Specialist Palliative Care in Eastern Hertfordshire that has a population of around 358, 000.

From October 2010 to June 2012 the Isabel Hospice Clinical Nurse Specialists provided benefits assistance to more than 1,700 clients. The Benefits Advisor was then able to offer more specialist advice to 400 clients.

It is imperative that the Benefits Advisor role is kept fully up to date with welfare reform and able to ensure that the Clinical Nurse Specialists are kept updated with changes.

It is estimated that the annual amount awarded to those under the care of Isabel Hospice as a result of the Partnership was in excess of $£ 368,000$. The top five benefits in which assistance has been given were for Disability Living Allowance, Carers Allowance, Bereavement Support and funeral payments, council tax benefit and employment allowance.

The Partnership has enabled the East Herts Citizens Advice Service to reach clients that it would not have been able to before. At such a stressful time it can be difficult to fit in a further appointment or even travel to the EHCAS - working collaboratively has enabled more patients and carers to receive the appropriate services to enhance the challenges faced when living with Life Limiting Illness either in the home, Day Services or our In- patient Unit.

P93 THE HOSPICE OF ST FRANCIS SPRING CENTRE: COLLABORATIVELY REACHING MORE PEOPLE 